\title{
PROSODIC CORRELATION BETWEEN THE FOCUSING ADVERB OZIK 'ONLY' AND FOCUS/GIVENNESS IN KOREAN
}

\author{
LEE, Yong-cheol* \\ University of Pennsylvania
}

\begin{abstract}
This study investigates the prosodic correlation between the focusing adverb ozik 'only' and focus/GIVENness in Korean. The goal is to test the issue of whether or not the element associated with ozik can be dephrased in Korean. This question is answered by a perceptual experiment in which the pitch contours of target sentences (i.e. Jeoneun ozik gichareul tamnida 'I only take the train' and Jeoneun ozik daehanhanggongeul iyonghamnida 'I only take Korean Air.') are modified using Praat. The modified sentences are embedded in two competing contexts in which focus/GIVENness on the element associated with ozik (i.e. gichareul 'the train', daehanhanggongeul 'Korean Air') is elicited. The results reveal that DoubleH (where both the focusing adverb and the object have prosodic prominence) is shown to be the most favored prosodic model when the element associated with ozik is focused in discourse. Conversely, OzikH (where the focusing adverb has prosodic prominence) is shown to be most favored when the element associated with ozik is GIVEN. Therefore, we argue that the element associated with ozik can be either prosodically prominent or dephrased depending on the discourse. This finding demonstrates that discourse functions such as focus and GIVENness are not directly contingent on the lexical semantics of the focusing adverb but instead are constrained by the discourse.
\end{abstract}

Keywords: focusing adverb, focus, GIVENness, prosody, discourse.

\footnotetext{
* Corresponding author: soongdora@gmail.com
} 


\section{Introduction}

It is known that the meaning of a sentence varies depending on the type of focusing adverb, such as only, also, or even (Krifka 2006, Hartmann and Zimmermann 2008). Consider the following examples.

(1) a. John only loves Mary.

b. John also loves Mary.

c. John even loves Mary.

What is common in (1) is the assertion that John loves Mary. However, the meaning of these sentences differs depending on the focusing adverb. For instance, the meaning of (1a) is John loves Mary and no one else. (1b) means that John loves Mary and someone else. (1c) also means that John loves Mary and someone else, but (1b) contrasts with (1c) in that the focusing adverb even signals that the assertion (i.e. John loves Mary) is unlikely. Therefore, the different interpretations of (1) demonstrate that focusing adverbs cause changes in the truth conditions of a sentence.

It is also known that focusing adverbs (e.g. only, also, even) are sensitive to the placement of focus, as shown in (2).

(2) a. Jan only gave Bill [money $]_{\mathrm{F}}$.

b. Jan only gave $[\text { Bill }]_{\mathrm{F}}$ money.

(Beaver et al. 2007:249)

In (2), the focused elements accompanied by prosodic salience are marked by a subscripted F. The interpretation of (2) varies depending on which element is focused. For example, if money receives focus, as shown in (2a), the meaning of the sentence is that all that Jan gave Bill was money. If focus is shifted from money to Bill, as shown in (2b), the sentence means that the one person Jan gave money to was Bill. Thus, (2) demonstrates that the prosodic marking from focus affects truth-conditional meaning.

While focusing adverbs are known to associate with focus, there has been a longstanding debate as to whether the element associated with only should be prosodically prominent. With reference to this debate, Rooth (1992) proposes two theories of focus: "weak" and "strong." A weak theory of focus interpretation stipulates a focused element in the domain of a focusing adverb such as only. Beaver and Clark $(2002,2003)$ claim that prosodic salience of a focused element is required for only to create an association. They test the phonetically reduced pronoun 'im to examine whether it is able to associate with 
only. ${ }^{1}$ The following context and example illustrate the interaction between only and the weak pronoun 'im (Beaver and Clark 2003:343).

(3) Context: You had many discussions with Sandy, but what I want to know is the extent to which you talked about Fred. Of all the times you talked with Sandy, how often was Fred the person you talked about?

(4) \#I [only $]_{F}$ discussed'im with Sandy.

Beaver and Clark (2003) argue that prosodic prominence on only is natural since it has not been mentioned in the previous context and is also the answer to the wh-question. As is shown, (4) is deemed infelicitous since the element associated with only (i.e. 'im) does not have prosodic prominence. Therefore, in this context, it seems reasonable to say that the element associated with only should be prosodically prominent.

Alternatively, according to the strong theory of focus, the element associated with only does not have to be prosodically prominent, rather the marking of focus may be contextually determined (Büring and Hartmann 2001, Kadmon, 2001, Rooth 1992, Schwarzschild 1997, Sudhoff 2010). Consider the following example (Rooth 1992:109).

(5) People who $[\text { grow }]_{\mathrm{F}}$ rice generally only $[\text { eat }]_{\mathrm{F}}$ rice.

In (5), the weak theory of focus would predict that the element rice should be focused since it is associated with the focusing adverb only. However, the marking of focus falls on the verb eat since it contrasts with grow in this specific context. The NP rice is not prosodically prominent, although it is associated with only. Thus, focus effects are said to be marked in context.

In related work, Kadmon (2001) proposes a theory on discourse congruence that the marking of focus is directly contingent on the discourse context, in which the position of focus determines whether or not the marking of focus is felicitous. Consider (6).

\footnotetext{
${ }^{1}$ In this sentence, 'im is a reduction of him. 
(6) a. John introduced Steve to Sue.

b. Oh no, John introduced $[\text { Bill }]_{\mathrm{F}}$ to Sue.

c. \#Oh no, John introduced Bill to [Sue $]_{\mathrm{F}}$.

(Kadmon 2001:334)

In (6b), Bill contrasts with Steve in the discourse; thus, the marking of focus on Bill is felicitous. In contrast, (6c) is deemed infelicitous since Sue does not reflect contrast. Kadmon's theory on discourse congruence is along the lines that " $[t]$ he focus is licensed in an utterance by a principle that relates that utterance to prior discourse" (Schwarzschild 1997:4).

In this study, we evaluate the two theories of focus (i.e. "weak" vs. "strong") regarding the issue of whether the element associated with ozik 'only' should be prosodically prominent. This study is accomplished by investigating the relationship between the focusing adverb ozik and focus/givenness in Korean, using a perception study of prosody. In relation to the purpose of the study, it is necessary to review the notions of focus and givenness; thus, section 1.1 covers the differences between them. In section 1.2, we consider the prosodic realizations of focus and givenness based on acoustic and auditory status. In section 1.3, we examine second occurrence focus, which is semantic focus and occurs when an element that has been already mentioned in discourse associates with a focusing adverb such as only. Finally, section 1.4 presents research questions.

\subsection{What is focus?}

Halliday (1967) defines focus as denoting new information or the most crucial element in a sentence. With this definition, Halliday separates sentences into "new" and "given" sections. The new information is textually non-recoverable from the previous context, while the given information is textually recoverable. Additionally, Jackendoff (1972) defines new information as the element that is not shared between the speaker and the hearer. Haviland and Clark (1974) suggest that new information is newly introduced into the hearer's knowledge, whereas given information is what the hearer already knows from the previous context. Thus, the placement of focus determines if the examples (7b) and (7c) are appropriate for the question (7a).

(7) a. What is his name?

b. His name is $[\text { Andrew }]_{\mathrm{F}}$.

c. \#[His name $]_{\mathrm{F}}$ is Andrew. 
In (7b), the NP Andrew is marked by focus since it is new information, whereas the rest is given information serving as the background of the answer. In (7c), the marking of focus on his name is deemed infelicitous since it is given information. (7) demonstrates that appropriate prosody plays an important role in the question-answer pairs in which it is used. An immediate question arises as to whether or not given information can occur with prosodic prominence.

Previous studies have found that given information can also attract prosodic prominence when it reflects contrast (Lee 2003, Rochemont and Culicover 1990, Selkirk 2008). Contrastive focus is a type of focus whose function is to refer to an exhaustive choice of a set of alternatives. Consider the following examples (Selkirk 2008:10).

(8) a. Mrs. Dalloway invited William and a group of his friends to her party.

b. But she only [vp $\left.\left.[\text { introduced Anabel to [William }]_{\mathrm{CF}}\right]\right]$.

In (8), a subscripted CF represents the CF-marked element. As shown in (8b), William is given information since it has been already mentioned in the discourse. However, it is an exhaustive choice between many people at the party since Mrs. Dalloway introduced Anabel to William and no one else. In Rooth's (1992) alternative semantics for focus, the focus semantic value for the verb phrase [vp [introduced Anabel to [William $\left.]_{\mathrm{F}}\right]$ ] constitutes the set of verb phrases of the form "introduced Anabel to $x$." The contrastive focus on William in (8b) would include a set of alternatives: \{introduced Anabel to William, introduced Anabel to John, introduced Anabel to Michael, ... \}. Therefore, William exhibits intonational prominence since it reflects contrast.

Contrastive focus is also found in alternative disjunctive questions, as in (9). ${ }^{2}$

(9) a. agi-ga don-eul meonjeo jib-eot-ni pen-eul meonjeo jib-eot-ni? baby-NOM money-ACC first pick-PST-Q pen-ACC first pick-PST-Q

'Did the baby pick the money first or did she pick the pen first?'

(Lee 2003:5)

b. agi-ga [don-eul $]_{\mathrm{CF}}$ meonjeo jib-eoss-e

baby-NOM money-ACC first pick-PST-DECL

'The baby picked the money first.'

(Lee 2003:6)

\footnotetext{
${ }^{2}$ Abbreviations used in this study: NOM (Nominative), ACC (Accusative), PST (Past), Q (Question), DECL (Declarative), TOP (Topic), HON (Honorific). Note that Korean sentences are Romanized based on the Revised Romanization of Korean as suggested by a reviewer.
} 
In (9b), the alternative pen-eul 'pen' is excluded and don-eul 'money' is an exhaustive choice of an alternatives set. Thus, the NP don-eul is marked by contrastive focus although it is given information. Lee (2003) argues that in Korean, the CF-marked element is realized with a focal accent.

Before turning to the next section, it is necessary to distinguish between his name in (7b) and William in (8b). What is common between them is that they are textually recoverable from a prior context. The difference is, however, that William in (8b) is focused, whereas his name in (7b) is not. Schwarzschild (1999) argues that what is not focused must be GIVEN. This study adopts the terminology (i.e. GIVENness) from Schwarzschild, thus distinguishing between his name in (7b) and William in (8b). Explicitly, his name in (7b) is GIVEN as it is not focused. William in (8b) is not GIVEN as it is focused. In what follows, we examine the prosodic realizations of focus and GIVENness based on acoustic and auditory dimensions.

\subsection{Prosodic realizations of focus and GIVENness}

It is understood that a focused element is generally marked with prosodic prominence. However, the prosodic realization of focus varies depending on the intonational phonology of the language - e.g. languages are largely classified as "head-prominent" and "edge-prominent" (Jun 2011). The former includes languages such as English and Dutch, in which focus is marked by a pitch accent. In these languages, a pitch accent falls on the primary stressed syllable of the focused element. Consider the English examples, in which the stressed syllables are marked by capitalization.

(10) a. John only loves $\left[\mathrm{MAry}_{\mathrm{i}}\right]_{\mathrm{F}}$

$\mathrm{H}^{*}$

b. But, Bill [HAtes $]_{\mathrm{F}}$ Mary .

$\varnothing$

In (10a), the NP Mary is realized with a pitch accent, $\mathrm{H}^{*}$. On the other hand, (10b) demonstrates that if focus is shifted from Mary to hates, then Mary is deaccented since it has been already mentioned in a prior context. In head-prominence languages, the GIVEN information such as Mary in (10b) is characterized by deaccentuation. According to Avesani and Vayra (2005:19), "[d]eaccenting is defined as the absence of a pitch accent on a word." Baumann (2005) argues that deaccentuation is appropriate to mark GIVEN information. Hirschberg and Ward (1991) also claim that deaccentuation functions as an anaphoric device. 
In edge-prominence languages such as Korean and Japanese, focus is realized by prosodic phrasing, which is demarcated through intonational prominence the edge of a phrase. In these languages, a strong phrase boundary is inserted into the focused area, where a focused element shows a larger pitch range than its non-focused counterpart. ${ }^{3}$ Figure 1 shows the prosodic differences between a non-focused and focused element in Korean. ${ }^{4}$ In Figure 1, the pitch range is expanded through the entire focused element (i.e. mandureul 'dumplings') in the third area, as opposed to head-prominence languages, in which the primary stressed syllable bears prosodic prominence.

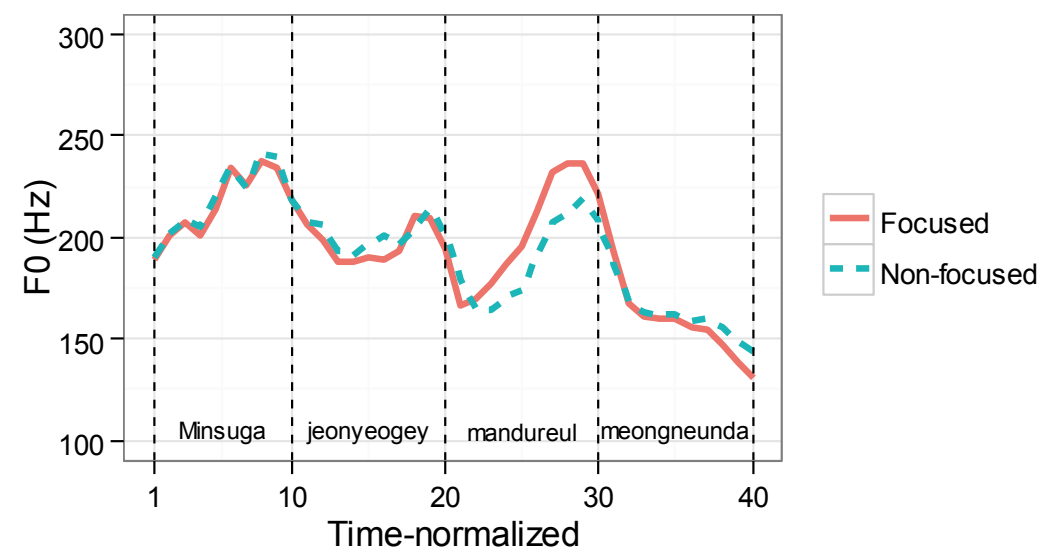

Figure 1. Time-normalized average F0 contours of 36 repetitions of the sentence Minsuga jeonyeogey mandureul meongneunda ('Minsu is eating dumplings in the evening.') by six speakers (modified from Lee and Xu 2010).

In edge-prominence languages, GIVEN information is characterized by dephrasing, which is the absence of accentual phrase boundaries (Ladd 1996). Consider the following examples.

(11) a. sachon-eonni ireum-i mueo-ni $\rightarrow$ \{sachon-eonni $\}\{$ ireum-i $\}\{$ mueo-ni $\}$ cousin-old sister name-NOM what-Q'

'What is sister-cousin's name?

b. sachon-eonni ireum-i suni-ji $\rightarrow\{$ sachon-eonni ireum-i $\}$ suni-ji\} cousin-old sister name-NOM Suni-DECL'

'Sister-cousin's name is Suni.'

(Jun 1993:199)

\footnotetext{
${ }^{3}$ Note that a non-focused element is different from GIVEN information in this study. A non-focused element is defined as one that does not receive focus from context, but is not GIVEN information. Therefore, it does not have to be prosodically weaker than GIVEN information.

${ }^{4}$ In Figure 1, the F0 contours were extracted by a Praat script (Xu 2005-2012). The vertical line borders each word in the sentence, where each area was time-normalized with the same number of points (10) at equally divided intervals.
} 
In (11), the accentual phrase is represented by curly brackets. ${ }^{5}$ In (11a), the NP ireumi 'name' is new information, thus forming an accentual phrase. However, since ireumi in (12b) is GIVEN, the accentual phrase of the NP is dephrased. ${ }^{6}$ The NP combines with the preceding phrase, and then the two phrases form one accentual phrase. Jun (2011) argues that a dephrased phrase such as ireumi in (11b) is realized with a substantially lowered/reduced pitch range.

Previous studies have also paid attention to the auditory perception of focus and GIVENness and have found that the distinction between them is well perceived. Fowler and Housum (1987) find that English listeners can distinguish between focus and GIVENness by prosody. Nooteboom and Kruyt (1987) investigate the prosodic status of focus and GIVENness in Dutch, conducting an acceptability judgment test. They observe that Dutch listeners interpret new information as natural when it is focused, and they interpret GIVEN information as plausible when it is deaccented. Likewise, it has been observed that the prosodic behavior of focus is proven to be perceptually salient in many languages, including Dutch (Krahmer et al. 2002, Nooteboom and Kruyt 1987), English (Bartels and Kingston 1994, Fowler and Housum 1987), French (Dohen and Lovenbruck 2009), Korean (Lee and Nambu 2012), Mandarin Chinese (Liu 2009), Vietnamese (Jannedy 2007), and others. Additionally, GIVENness has been proven perceptually distinctive with a substantially lowered pitch range in several languages, such as Dutch (Krahmer and Swerts 2001, Nooteboom and Kruyt 1987), English (Cruttenden 2006, Fowler and Housum 1987), German (Baumann 2005, Baumann and Hadelich 2003), and Korean (Lee and Nambu 2012). In the next section, we discuss the notion of second occurrence focus and examine the prosodic realization of second occurrence focus. Furthermore, we address problems with the weak theory of focus interpretation based on the prosodic behavior of second occurrence focus.

\subsection{Second occurrence focus}

Second occurrence focus (henceforth SOF) is semantic focus and occurs when an element which has already been mentioned in discourse associates with a focusing adverb such as only. Consider the following examples.

\footnotetext{
${ }^{5}$ Schafer and Jun (2002) observe that in Korean, every phrase of a sentence can form a separate accentual phrase. In Figure 1, we see that each phrase (except the sentence-final one), as delimited by the vertical lines, has a rising-falling F0 contour with one or two peaks, regardless of the focus condition. The one or two peaks show the evidence that each phrase of a sentence forms a separate accentual phrase.

${ }^{6}$ Ladd (1996) argues that Korean dephrasing corresponds to English deaccenting, saying that they are just different surface realizations of the same underlying effects.
} 
(12) a. Eva only gave xerox copies to [the graduate students $]_{\mathrm{F}}$.

b. (No,) PETER only gave xerox copies to [the graduate students] $]_{\text {SOF }}$.

(Partee 1999:31)

In (12), a subscripted F and SOF mark the focused element and the SOF element, respectively. It is understood that the focused phrase the graduate students in (12a) is characterized by prosodic prominence. However, there still remains a question as to whether SOF is prosodically prominent or not. According to the weak theory of focus, there must be a prosodically prominent element associated with only. In this case, it is assumed that SOF receives prosodic prominence by virtue of being associated with only. Alternatively, according to the strong theory of focus, the element associated with only does not have to be prosodically prominent. Instead, the marking of focus may be contextually constrained. If this is the case, the graduate students in (12b) may not be prosodically prominent because it has already been mentioned and is not in a contrastive relationship.

Regarding the phonetic realizations of SOF, previous studies have not reached a consensus on the prosodic prominence of SOF based on its phonetic realizations. Krifka (2004) and Partee (1991) argue that SOF is not prosodically prominent. Other authors, such as Bartels (2004) and Beaver et al. (2007), claim that SOF has a longer duration and a greater intensity than non-focused elements, although it does not contain a contrastive pitch accent. Jackendoff (1972) argues that if a certain element bears focus in its syntactic domain (i.e. F-marked), then the element must be realized with prosodic prominence. If Jackendoff's claim is correct, then the graduate students in (12b) should be prosodically prominent. In this study, therefore, we investigate whether elements such as the graduate students in (12b) actually exhibits prosodic prominence. Consider the following examples (Féry and Ishihara 2009:289).

(13) a. Mary's boyfriend only likes her.

b. Even her boss only likes her.

c. \#Even her boss only likes'er.

As shown, (13c) is infelicitous because the reduced pronoun 'er does not bear any prosodic prominence, and thus, it cannot associate with only. Authors such as Beaver and Clark (2002, 2003), Krifka (2004), and Rooth (1996) argue that the element associated with only needs to be prosodically prominent. Nevertheless, (13a) and (13b) demonstrate that only can associate with her. Pronouns are anaphoric and thus show reduced pitch values. If this is the case, then we argue that the element associated with only can be dephrased. 


\subsection{Research questions}

Thus far, we have examined the two theories of focus ("weak" vs. "strong") on how association with focus is established in grammar. From the weak theory of focus point of view, the element associated with only must be prosodically prominent. In the other view, the element associated with only does not have to be prosodically prominent. Moreover, we have discussed the prosodic properties of discourse-new and contrastive focus versus GIVENness. Both contrastive and discourse-new focus attract prosodic prominence, whereas GIVENness is realized with reduced pitch values.

We have found that previous studies have not reached an agreement on the prosodic behavior of SOF. It has been observed that the prosody of SOF is not prosodically prominent (Krifka 2004, Partee 1991). In contrast, while there is no contrastive pitch accent on the SOF element, it is distinguished by other parameters such as duration and intensity (Bartels 2004, Beaver et al. 2007). Additionally, since reduced pronouns such as 'im and 'er cannot be associated with only, it has been argued that the element associated with only should be prosodically prominent (Beaver and Clark 2002, 2003, Krifka 2004, Rooth 1996).

Based on the background information, we formulate a research question: Can the element associated with Korean ozik be dephrased ${ }^{7}$ If the answer is yes, the strong theory of focus interpretation

\footnotetext{
${ }^{7}$ A reviewer claimed that in Korean, the correlation between prosody and focus/GIVENness can be predicted by morpho-syntactic cues. This claim may be true, but there are several cases when prosodic cues are deemed more important than morpho-syntactic cues. We hereby present two cases:
}

First, prosody helps to disambiguate a syntactic ambiguity. Consider (i).

(i) hyeonmyeonghan agi-ui appa

wise baby-Gen daddy

'the [wise baby's] daddy' or 'the wise [baby's daddy]

(Schafer and Jun 2002:229)

As shown in (i), the adjective hyeonmyeonghan modifies the first noun (agi) or the complex noun (agi-ui appa). Schafer and Jun (2002) argue that syntactic information does not resolve a syntactic ambiguity, but instead prosody helps listeners to parse the ambiguous structure.

Second, prosody varies depending on the informational status of a sentence. In the K-ToBI system (Jun 1993, 1998, 2006), a three-syllabled accentual phrase shows a high tone $(\mathrm{H})$ at the edge of the constituent regardless of whether the accentual phrase includes a suffix (gicha-reul) or not (bihaenggi- $\emptyset$ ). Consider the following example:

(ii) a. Jeo-neun gicha-reul tam-ni-da. (non-focus) I-Top train-Acc take-Hon-Decl 'I take the train.'

b. Jeo-neun [gicha-reul $]_{\mathrm{F}}$ tam-ni-da. (narrow focus)

c. Jeo-neun [gicha-reul] $]_{\mathrm{G}}$ tam-ni-da. (GIVENness)

In (iia), when the sentence is in a non-focus condition, gichareul exhibits a high tone at the edge of the constituent. However, when gichareul has narrow focus (iib), the pitch range of the constituent is significantly more expanded than that in the non-focus condition. Whereas, when the equivalent element is GIVEN (iic), it is characterized with a substantially reduced pitch range. That is, the three-way distinctions between non-focus, narrow focus, and GIVENness are made by only prosodic cues. In the case of (ii), morpho-syntactic cues do not provide detailed information since the structure is morphologically and syntactically the same. The 
will win out. Conversely, the weak focus of theory will be justified if the element associated with ozik should not be dephrased. To address the issue, we modify pitch contours of ozik and the element associated with the focusing adverb. The goal of the current study is completed through a naturalness rating experiment.

\section{Methodology}

\subsection{Fo Modification}

This study consisted of two target sentences: i) Jeoneun ozik gichareul tapnida 'I only take the train'; ii) Jeoneun ozik daehanhanggongeul iyonghapnida 'I only take Korean Air. ${ }^{8}$ The target sentences were recorded by the author, a 31-year-old non-professional Korean native speaker. During the recording session, three different sound samples were produced to be employed for F0 modification. The first sample had a high tone on ozik, but a low tone on the object for $O z i k H$. The second had a low tone on ozik, but a high tone on the object for Object $H$. The last sample had a high tone on ozik and another high tone on the object for DoubleH. After the recording was complete, the pitch contours of the original utterances were modified using a TD-PSOLA (Time Domain Pitch Synchronous Overlap-Add) synthesis function through Praat (Boersma and Weenik 1992-2012). The reason behind the modification was that it is difficult or maybe implausible for a non-professional speaker to control the vocal cords to create specific F0 values for the high and low tones. For example, DoubleH is the prosodic model where both the focusing adverb and the object have prosodic prominence. Although two focal accents are supposed to be placed on the focusing adverb and the object, if one focal accent is perceived as prosodically more prominent than the other, then it is unlikely that listeners would evaluate this case as DoubleH. Additionally, $O c i k H$ is the prosodic model where only the focusing adverb has prosodic prominence. But, unless the high tone on ozik is not perceived as prosodically more prominent that the low tone on an object, it is also unlikely that listeners evaluate this case as $O z i k H$. In order to prevent the unwanted effects of the original utterances, we purposefully employed the TD-PSOLA synthesis function through Praat.

test materials in this study are relevant to the examples in (ii). We argue that even the same structure exhibits different prosodic effects depending on the informational status regulated by discourse contexts. The goal of this study was to therefore test whether or not this claim can be substantiated.

${ }^{8}$ A reviewer suggested that the sentences (e.g. Jeoneun ozik gichareul tamnida.) tested in this study may not be the best choice in a spoken language. But instead, to construct a more natural sentence, the reviewer proposed to attach a restrictive suffix (-man) to lexical items, such as Jeoneun gichaman tamnida. This idea is completely acceptable. However, there is a specific and an important motive in utilizing a focusing adverb (ozik) instead of -man. As noted before, focus in Korean is characterized by prosodic phrasing with intonational prominence at the edge of a phrase. Let us examine a sentence Jeoneun gichaman tamnida as an example. In this sentence, when kicha 'the train' is focused, prosodic prominence occurs at the edge of the constituent gichaman. When -man is focused, prosodic prominence also occurs at the edge of the constituent just as before. This scenario would inadvertently raise a confounding effect that may take place when employing -man. In order to eliminate the confounding effect, we did not attach -man to lexical items.

JoSS 2(2): 85-111. 2012. 
Figure 2 shows how we modified the pitch contours.

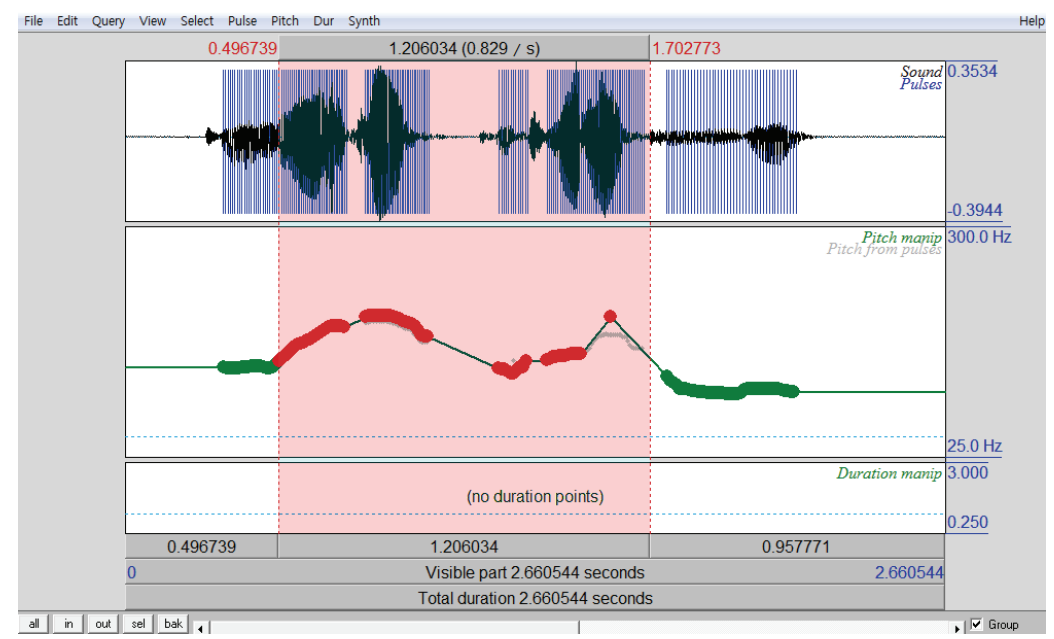

Figure 2. A snapshot of the TD-PSOLA synthesis function.

The target sentence is Jeoneun ozik gichareul tapnida 'I only take the train.'

In Figure 2, the shaded area indicates the target words ozik gichareul and the gray dots indicate the original pitch contour of the third syllable of gichareul. It is shown that the F0 peak of gichareul is lower than that of ozik. Using the TD-PSOLA synthesis function, we were able to modify the F0 peak of gichareul properly. ${ }^{9}$ Based on the F0 modification, we provided three different prosodic models: OzikH

\footnotetext{
${ }^{9}$ A reviewer expressed concern with the use of synthetic/resynthesized speech in the perception experiment. The reviewer suggested that we run a control experiment to test whether or not there was degradation (e.g. metallic or robotic sounds) in the modified stimuli. Following the reviewer's suggestion, we did a control test. The result showed that there was no degradation of the synthesized stimuli.

Fifteen native Korean speakers, nine females and six males between the ages of 20 and 31, evaluated the naturalness of both the six modified stimuli and the six natural stimuli used in the study. The stimuli were presented to the subjects in a randomized order with no context. The subjects rated each stimulus using a seven-point scale (very natural" = 7; "natural" =6; "somewhat natural" $=5$; "neither natural nor unnatural" $=4$; "somewhat unnatural" $=3$; "unnatural" $=2$; "very unnatural" $=1$ )

The mean value of the modified stimuli was 3.63 and that of the original stimuli was 3.56. A comparison of these two values unexpectedly reveals the mean value of the naturalness of modified speech as even greater than that of original speech. A paired $t$ test shows that there is no significant difference between them $(t[89]=0.53, p=0.57)$. The result suggests that the modified stimuli are not degraded.

A question remains as to why the overall rating of modified and original speech is relatively both low. Table $i$ displays the mean value of each category by listener. We see that although "very" low ratings were given by some listeners such as L5, L12, and L13, most of the listeners overall gave low ratings, except the listeners L7 and L8. As noted before, we placed a focal accent on ozik, the object, or both, for the purpose of our current study. While a focal accent may sound natural when presented in an appropriate context, it is not generally used in an isolated context. We speculate that this is the reason the participants rated modified and original speech as relatively low.
}

Table i. The mean value of the naturalness of modified and original speech by listener

\begin{tabular}{cccccccccccccccc}
\hline & L1 & L2 & L3 & L4 & L5 & L6 & L7 & L8 & L9 & L10 & L11 & L12 & L13 & L14 & L15 \\
\hline Original & 3.8 & 4.0 & 3.5 & 4.2 & 1.7 & 3.0 & 5.2 & 5.8 & 4.2 & 3.7 & 3.0 & 1.3 & 2.0 & 4.5 & 3.5 \\
Modified & 2.7 & 3.7 & 3.8 & 3.7 & 2.3 & 3.2 & 5.0 & 4.5 & 5.2 & 5.2 & 3.5 & 2.0 & 2.2 & 4.0 & 3.7 \\
\hline
\end{tabular}


(the focusing adverb has prosodic prominence), ObjectH (the object has prosodic prominence), and DoubleH (both the focusing adverb and the object have prosodic prominence). Figure 3 displays the three prosodic models.
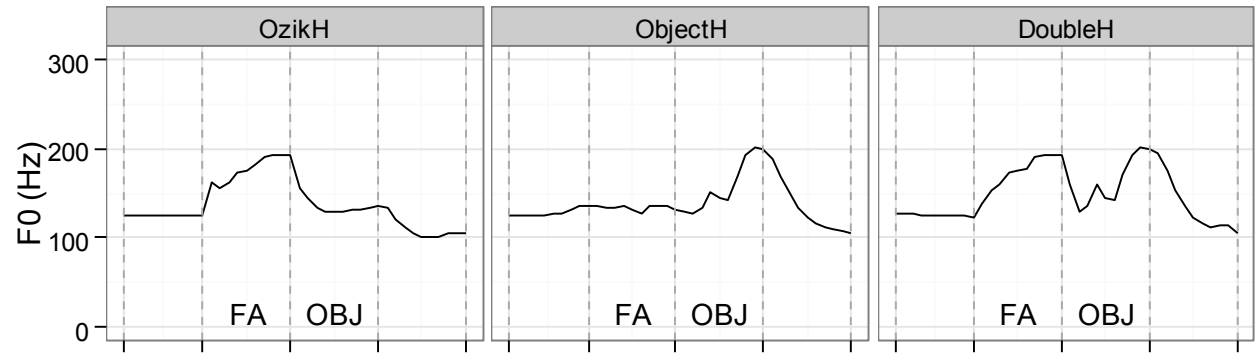

(a)
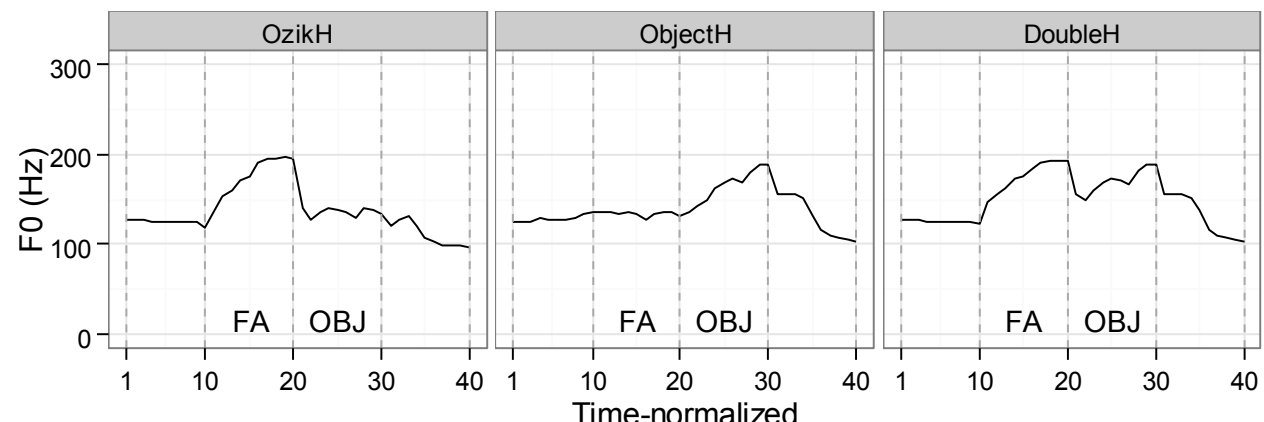

(b)

Figure 3. The time-normalized F0 contours are grouped by target sentence. The F0 contours on the top (a) indicate the sentence Jeoneun ozik gichareul tamnida 'I only take the train.' The F0 contours on the bottom (b) indicate the sentence Jeoneun ozik daehanhanggongeul iyonghamnida 'I only take Korean Air.' FA and OBJ denote the focusing adverb (ozik 'only') and the object (gichareul 'the train' or daehanhanggongeul 'Korean Air'), respectively.

Table 1 tabulates the mean and maximum pitch values of the $2^{\text {nd }}(\mathrm{FA})$ and $3^{\text {rd }}(\mathrm{OBJ})$ areas for each sentence in panels (a) and (b).

Table 1. The top panel (a) indicates the sentence Jeoneun ozik gichareul tamnida 'I only take the train.' The bottom panel (b) indicates the sentence Jeoneun ozik daehanhanggongeul iyonghamnida 'I only take Korean Air.'

\begin{tabular}{cccccc}
\hline & & \multicolumn{2}{c}{ Mean pitch values (Hz) } & \multicolumn{2}{c}{ Maximum pitch values (Hz) } \\
\cline { 3 - 6 } & & FP & OBJ & FP & OBJ \\
\hline \multirow{3}{*}{ (a) } & OzikH & 177.7 & 135.5 & 192.9 & 154.7 \\
& ObjectH & 133.6 & 159.2 & 136.2 & 201.1 \\
& DoubleH & 174.7 & 163.6 & 193.1 & 200.8 \\
\hline \multirow{3}{*}{ (b) } & OzikH & 177.2 & 135.8 & 196.9 & 141.2 \\
& ObjectH & 133.9 & 166.2 & 136.2 & 189.2 \\
& DoubleH & 176.4 & 170.3 & 193.1 & 189.2 \\
\hline
\end{tabular}




\subsection{Stimuli}

The three prosodic models were provided in competing discourse contexts. ${ }^{10}$ In the first context, the element associated with ozik was designed to be either discourse-new (14a) or contrastive (15a). In the second context, the equivalent element was designed to be GIVEN. For example, in (14a), gichareul 'the train' receives discourse-new focus since it is new information. In (15a), daehanhanggongeul 'Korean Air' receives contrastive focus since it reflects contrast. However, in (14b) and (15b), gichareul and daehanhanggongeul are GIVEN since they have been mentioned in the previous discourse and are not involved in a contrastive relationship. 12 sound files ( 3 modified prosodic models $\times 2$ target sentences $\times 2$ discourse contexts) served as the target stimuli, and another set of 12 sound files were used as fillers. In total, this study includes 24 sound files. (14) and (15) show the discourse contexts, in which the target sentences are in boldface, and the elements associated with ozik are in square brackets. The subscripted F, $\mathrm{G}$, and CF represent discourse-new focus, GIVENNESS, and contrastive focus, respectively.

(14) a. Discourse-new focus (The element associated with ozik 'only' is discourse-new.)

I am attending Hannam University in Daejeon. However, my parents live in Seoul, my younger brother lives in Busan, and my older brother lives in Daegu. So, on major holidays, such as Christmas and New Year's Day, I may go to Seoul, Busan and Daegu to visit my family. When going to Seoul to see my parents, I only take [the train $]_{F}$.

b. GIVENness (The element associated with ozik 'only' is GIVEN.)

My father works for Korail. According to Korail regulations, my family gets free train tickets. I take business trips to Seoul. So, whenever I go to Seoul, I only take [the train $]_{\mathrm{G}}$.

(15) a. Contrastive focus (The element associated with ozik 'only' is contrastive.)

I am attending the University of Pennsylvania in Philadelphia. However, since my parents live in Korea, I go to Korea to see them every school vacation. I have both Korean Air and Delta Airline membership cards. When I go to Korea, I only take [Korean Air $]_{\mathrm{CF}}$.

b. GIVENness (The element associated with ozik 'only' is GIVEN.)

I am attending Columbia University in New York. However, since my parents live in Korea, I go to Korea to see them every school vacation. Because I have a Korean Air membership card, I don't take other airlines. So, whenever I go to Korea, I only take [Korean Air] $]_{\mathrm{G}}$.

\footnotetext{
${ }^{10}$ For the sake of simplicity, we only provide English translations. Korean sentences used for the perception experiment are shown in the Appendix, along with the Revised Romanization of Korean.
} 


\subsection{Subjects}

Twenty native speakers of Korean (12 females and 8 males) participated in this perception experiment. They were between 21 and 37 years old when the experiment was conducted. The participants were naïve to the purpose of the experiment. They were recruited at Hannam University and were paid for their participation. Before the experiment, consent forms were obtained from each participant. None of the participants reported problems with their hearing.

\subsection{Procedure}

We conducted a rating experiment using a 7-point scale ("very natural" $=7$; "natural" $=6$; "somewhat natural" $=5$; "neither natural nor unnatural" $=4$; "somewhat unnatural" $=3$; "unnatural" $=2$; "very unnatural" = 1). The experiment was made using PowerPoint slides. Figure 4 is a screenshot of the perception experiment. On top of the screenshot are instructions for the procedure. The middle of the screenshot displays the discourse context. At the bottom is a sound icon, which when clicked, plays a sound file through the computer.

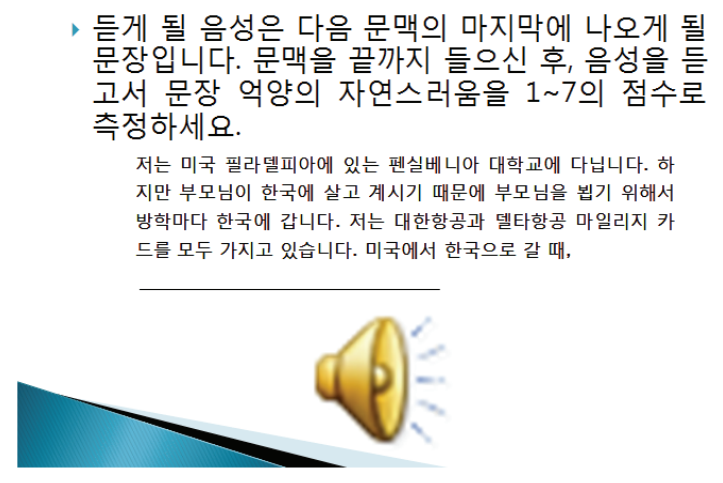

Figure 4. A screenshot of the perception experiment. ${ }^{11}$

Participants first participated in a trial test before the actual experiment in order to become familiar with the procedure of the experiment. Second, participants listened to the discourse context said aloud by the author, and they were also allowed to read the discourse context whenever necessary. Following the discourse context, a target sentence was played through a computer. Note that the target sentences were not shown on the PowerPoint slides. Listeners were asked to rate the naturalness of the target sentences

\footnotetext{
${ }^{11}$ The top of the screenshot can be translated as follows: "The following sound file to be played will occur right after the discourse context. After you listen to the discourse context, please rate the naturalness of the sound file." The middle of the screenshot can be translated as follows: "I am attending the University of Pennsylvania in Philadelphia. However, since my parents live in Korea, I go to Korea to see them every school vacation. I have both Korean Air and Delta Airline membership cards. When I go to Korea, "
} 
based on the discourse context. The 24 sound files used for the experiment were presented in randomized order. The answer sheet was presented on paper. They were allowed to listen to the same target sentence up to three times until they felt confident about the judgment. The present experiment was conducted in a quiet room at Hannam University.

\subsection{Statistics}

The responses, based on a 7-point scale, were converted to z-scores to normalize the results across listeners. Schütze and Sprouse (to appear) find the $z$-score transformation useful since it is able to minimize the potential effect of scale bias, particularly when only some points are used on a 7-point scale (scale compression) or when only the low or high end of the scale is used (scale skew). $Z$-scores were calculated separately for each listener by applying the following equation:

(16) $z=\left(x-M \_l i s t e n e r\right) / S D \_$listener

where $M \_l i s t e n e r$ and $S D \_l i s t e n e r$ are the mean and the standard deviation of all responses by each listener.

There were two independent variables in this study: CONTOUR (OzikH, ObjectH, and DoubleH) and DISCOURSE (focus and GIVENness). The dependent variable was the $z$-score. In order to analyze the prosodic correlation of the focusing adverb and discourse functions in discourse, two-way repeated measures ANOVAs were conducted. Furthermore, we conducted multiple pairwise comparisons to find out which prosodic model was the most favored in a group under the effect of DISCOURSE.

\section{Results}

Figure 4 shows the sentence Jeoneun ozik gichareul tamnida 'I only take the train.' In this sentence, the element (i.e. gichareul) associated with ozik was designed to be discourse-new or GIVEN depending on the discourse context. Figure 5 shows the sentence Jeoneun ozik daehanhanggongeul iyonghamnida 'I only take Korean Air.' In this sentence, the element (i.e. daehanhanggongeul) associated with ozik was designed to be contrastive or GIVEN depending on the discourse context. Figures 5 and 6 display mean $z$ scores for each of the three prosodic models conditioned on the DISCOURSE factor. The standard error bars in both figures are represented based on the variability across all the prosodic models and listeners. We describe Figures 5 and 6 in turn. 


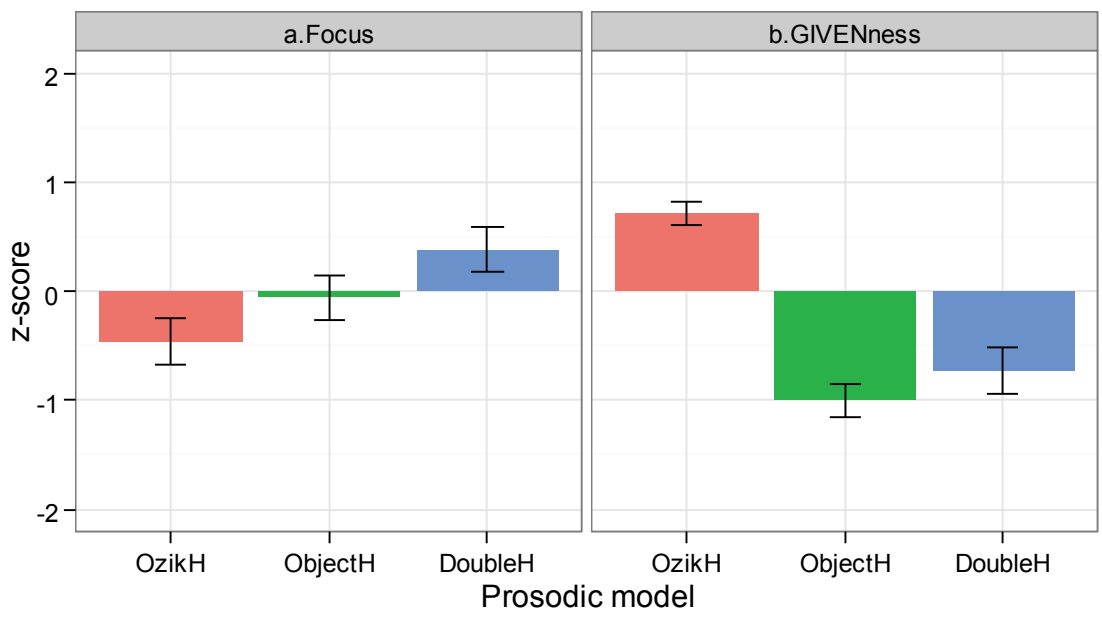

Figure 5. Z-score of DisCOURSE effect on the three prosodic models for the sentence Jeoneun ozik gichareul tamnida 'I only take the train.'

In Figure 5a, the mean value of $\mathrm{OzikH}$ is -0.46 . The mean value of $\mathrm{ObjectH}$ is -0.06 . The mean value of DoubleH is 0.38 . When gichareul is focused in context, DoubleH is shown to be the greatest, followed by ObjectH, and OzikH. On the other hand, when the element associated with ozik is GIVEN (Figure 5b), the mean value of $O z i k H$ is 0.72 . The mean value of ObjectH is -1.00 . The mean value of DoubleH is -0.72 . The results show the ordering of $\mathrm{OzikH}>\mathrm{DoubleH}>\mathrm{ObjectH}$, from highest to lowest. Let us now turn to Figure 6.

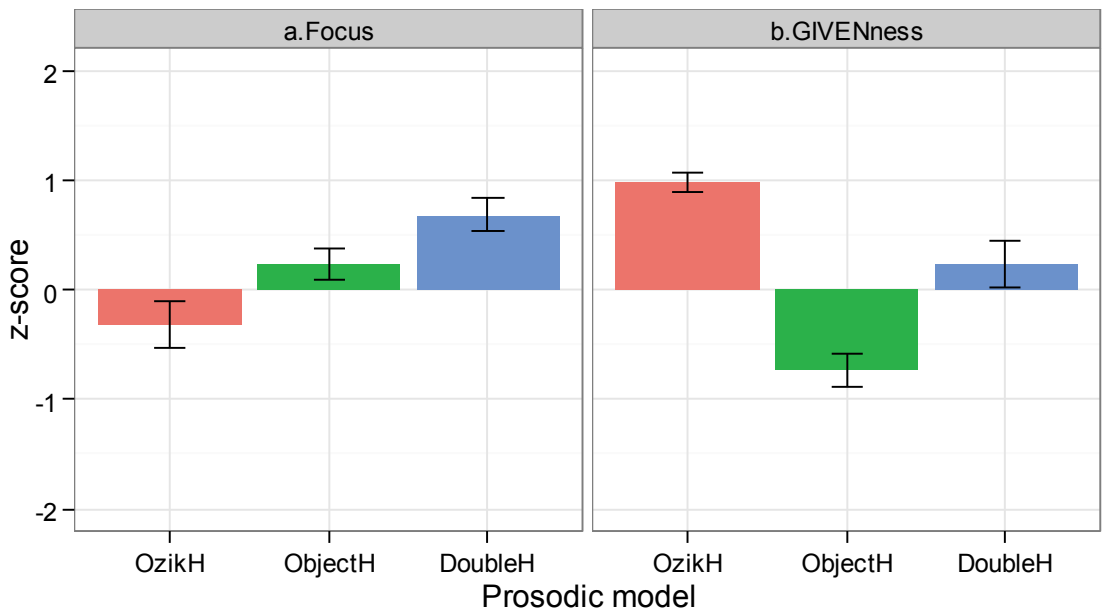

Figure 6. Z-score of effect of DiSCOURSE on the three prosodic models for the sentence Jeoneun ozik daehanhanggongeul iyonghamnida 'I only take Korean Air.'

In Figure 6a, the mean value of $O z i k H$ is -0.31 . The mean value of $O b j e c t H$ is 0.23 . The mean value of DoubleH is 0.68 . When daehanhanggongeul reflects contrast, DoubleH is shown to be the 
greatest, followed by $\mathrm{ObjectH}$, and $\mathrm{OzikH}$. When the corresponding element associated with ozik is GIVEN (Figure 6b), the mean value of $O z i k H$ is 0.98 . The mean value of ObjectH is -0.73 . The mean value of DoubleH is 0.23 . The mean values of the three prosodic models decrease in this order: $O z i k H>$ DoubleH $>$ Object $H$.

In both Figure 5a and $6 \mathrm{a}$, the results show little variance regardless of whether the focus is discourse-new or contrastive. That is, DoubleH has the greatest value, followed by ObjectH and OzikH. The same is true of the case when the element (gichareul or daehanhanggongeul) is GIVEN in context. In this case, the results of $\mathrm{OzikH}$ are the greatest, followed by DoubleH and ObjectH. This study does not aim to determine the differences between the focus types: discourse-new and contrastive. Therefore, we collapsed over the two focus types for further analyses. Figure 7 displays the results of the collapsed focus types.

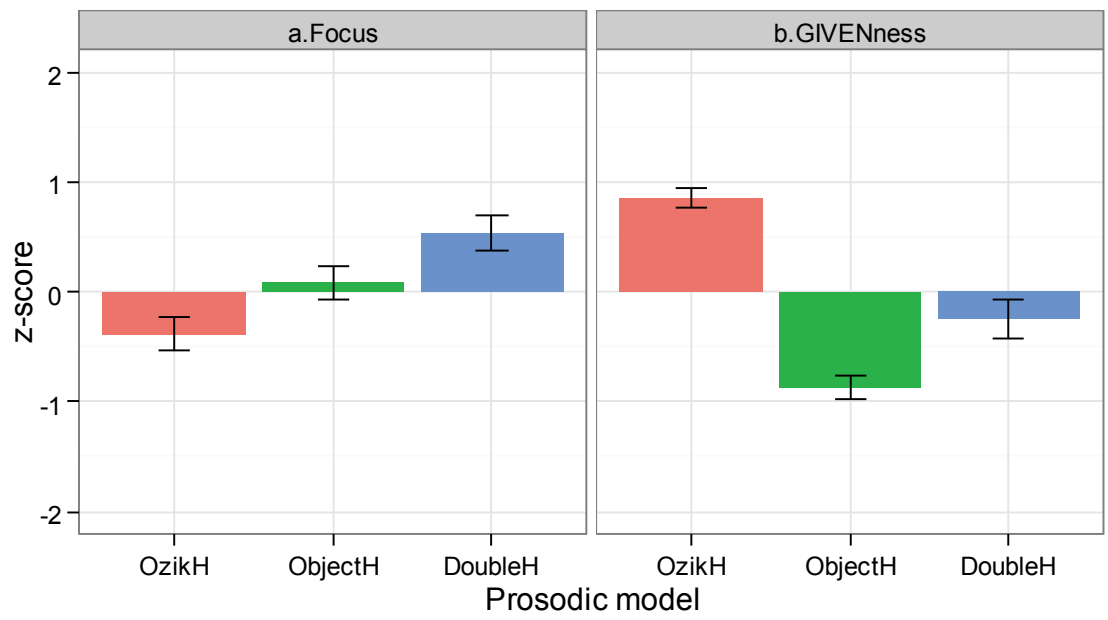

Figure 7. Z-score of effect of DiSCOURSE on the three prosodic models (collapsed).

In Figure 7a, when the element associated with ozik is focused in context, the mean values of OzikH, ObjectH, and DoubleH are $-0.39,0.08$, and 0.53 , respectively. In this case, the mean value of DoubleH is the greatest, followed by ObjectH, and $O z i k H$. On the other hand, when the element associated with ozik is GIVEN (Figure 6b), the ordering of $\mathrm{OzikH}>\mathrm{DoubleH}>\mathrm{ObjectH}$ is shown. Specifically, the mean values of $O z i k H, O b j e c t H$, and DoubleH are $0.85,-0.87$, and -0.25 , respectively.

Table 2 shows the results of a two-way repeated measures ANOVA. As is shown, the effect of CONTOUR is highly significant $(F[2,38]=9.069, p<0.001)$, but the effect of DISCOURSE is not significant $(F[1,19]=1.652, p=0.214)$. However, there is a highly significant interaction effect between CONTOUR and Discourse $(F[2,38]=43.49, p<0.001)$. That is, the three prosodic models (i.e. OzikH, ObjectH, DoubleH) can be said to be considerably affected by the discourse context. 
Table 2. Results of a two-way repeated measures ANOVA under the effects of CONTOUR and DiSCOURSE.

\begin{tabular}{cccccc}
\hline Source & Sum of squares & df & Mean square & F & Sig. \\
\hline CONTOUR (A) & 9.074 & 2 & 4.537 & 9.069 & $p<0.001$ \\
Subject error & 19.010 & 38 & 0.500 & & \\
\hline DISCOURSE (B) & 0.816 & 1 & 0.816 & 1.652 & $p=0.214$ \\
Subject error & 9.380 & 19 & 0.494 & & \\
\hline A x B & 29.681 & 2 & 14.841 & 43.492 & $p<0.001$ \\
Subject error & 12.967 & 38 & 0.341 & & \\
\hline
\end{tabular}

Next, Table 3 tabulates the results of multiple pairwise comparisons when the element associated with ozik is focused. In this context, Korean listeners evaluate DoubleH (z-score: 0.53 ) as the most favored prosodic model, whereas they evaluate $\operatorname{OzikH}(z$-score: -0.39$)$ as the most unlikely prosodic model. The naturalness of the three prosodic models, in this context, shows the ordering of DoubleH $>$ Object $H>$ OzikH.

Table 3. The differences in prosodic models when the element associated with ozik is focused.

\begin{tabular}{ccccc} 
& & & & $(\mathrm{df}=19)$ \\
\hline (A) contour (z-score) & (B) contour (z-score) & $\Delta(\mu \mathrm{A}-\mu \mathrm{B})$ & $\mathrm{t}$ & Sig. \\
\hline OzikH (-0.39) & ObjectH (0.08) & -0.471 & -1.969 & $p<0.05$ \\
OzikH (-0.39) & DoubleH (0.53) & -0.920 & -3.814 & $p<0.01$ \\
ObjectH (0.08) & DoubleH (0.53) & -0.449 & -2.111 & $p<0.05$ \\
\hline
\end{tabular}

On the other hand, when the element associated with ozik is GIVEN, it turns out that OzikH (z-score: 0.85 ), which has prosodic prominence on the focusing adverb, is shown to be the most favored prosodic model. Meanwhile in the same discourse context, we find ObjectH ( $z$-score: -0.87$)$ to be the most unnatural prosodic model. That is, when the element associated with ozik is GIVEN, the naturalness of the three prosodic models decreases in this order: $\mathrm{OzikH}>$ DoubleH $>$ ObjectH. 
Table 4. The differences in prosodic models when the element associated with ozik is GIVEN.

\begin{tabular}{ccccc} 
& & & $(\mathrm{df}=19)$ \\
\hline (A) contour (z-score) & (B) contour (z-score) & $\Delta(\mu \mathrm{A}-\mu \mathrm{B})$ & t & $p$-value \\
\hline OzikH (0.85) & ObjectH (-0.87) & -0.471 & -1.969 & $p<0.05$ \\
OzikH (0.85) & DoubleH (-0.25) & -0.920 & -3.814 & $p<0.01$ \\
ObjectH (-0.87) & DoubleH (-0.25) & -0.449 & -2.111 & $p<0.05$ \\
\hline
\end{tabular}

In summary, we have examined whether the element associated with the focusing adverb ozik is dephrased in Korean. To settle this issue, we designed two competing contexts. In the first instance, the element associated with ozik was designed to be focused. In the second instance, the corresponding element was designed to be GIVEN. The findings of this study provide the following rankings:

(17) The rankings of the three prosodic models

a. DoubleH $>$ ObjectH $>$ OzikH when the element associated with ozik is focused in context;

b. OzikH $>$ DoubleH $>$ ObjectH when the element associated with ozik is GIVEN in context.

\section{Discussion}

The results of the three prosodic models have provided supporting evidence that the element associated with ozik can be dephrased. With this evidence, we first evaluate the two theories of focus: "weak" and "strong." Second, we describe the naturalness of the prosodic models under the DiSCOURSE effect.

\subsection{How is association with focus established?}

As noted earlier, according to the weak theory of focus, there must be a prosodically prominent element associated with ozik. Alternatively, according to the strong theory of focus, the element associated with ozik does not have to be prosodically prominent, but rather the relationship between focus and background may be constrained in discourse. Following the results of this study, we support the strong theory of focus interpretation that the element associated with ozik does not always have to show prosodic prominence. We find that the element associated with ozik can be either prosodically prominent or dephrased depending on the context. Thus, focus and GIVENness can be said to be discourse-driven. We give two reasons for this position.

First and foremost, $\mathrm{OzikH}$, which has prosodic prominence on the focusing adverb, is shown to be the most favored prosodic model when the element associated with ozik is GIVEN. Authors such as Beaver and Clark (2002, 2003), and Jacobs (1984) argue that the element associated with only is semantically 
constrained by the focusing adverb. That is, a focusing adverb such as only requires a salient prosodic element in its domain to construct an association. The finding of $O z i k H$, however, casts doubt on the previous proposals because the element associated with ozik turns out to be dephrased when it is GIVEN in context. Said a different way, the finding of $\mathrm{OzikH}$ shows evidence that the element associated with ozik can be dephrased. Second, when the element associated with ozik is focused, DoubleH (where both the focusing adverb and the object have prosodic prominence) is shown to be the most natural prosodic model, as opposed to the finding of $\mathrm{OzikH}$ in the other context. That is, the same target sentences behave differently depending on the discourse context. This finding implies that discourse functions such as focus and GIVENness are not directly contingent on the lexical semantics of the focusing adverb. Instead, the relationship between focus and background is constrained in context, which is in agreement with previous findings (Büring and Hartmann 2001, Kadmon 2001, Schwarzschild 1997, Sudhoff 2010).

\subsection{Naturalness of prosodic models under the DISCOURSE effect}

We found that the three prosodic models are highly influenced by discourse context. For example, when the element associated with ozik is focused, DoubleH is shown to exhibit the most acceptable prosodic model. An obvious question to ask now is: why is DoubleH the most favored in this context? First, ozik has not been mentioned in the previous context. Therefore, it receives discourse-new focus due to its nature of novelty. ${ }^{12}$ Second, in the case of gichareul, it has not been mentioned in a prior context; it is obvious that the prosodic prominence on gichareul indicates discourse-new focus. As opposed to gichareul, daehanhanggongeul has been mentioned in the previous discourse but contrasts with Delta Airline in context. Hence, it receives contrastive focus. Therefore, DoubleH is most favored when the element associated with ozik is focused. However, in the same environment, OzikH, which has prosodic prominence on the focusing adverb, is shown to be most penalized. This is because $O z i k H$ indicates the prosodic model where the element associated with ozik lacks prosodic prominence. Thus, the low phrasal accent on the element associated with ozik is considered most unlikely.

In contrast, when the element associated with ozik is GIVEN, OzikH is shown to be the most acceptable prosodic model. As noted above, this can be explained by the discourse-new focus and presumably the contrastive focus of ozik. In contrast, in the same environment, ObjectH is shown to be most unlikely. This is because the element associated with ozik has already been mentioned in the

\footnotetext{
${ }^{12}$ It is reasonable to speculate that the prosodic prominence on ozik reflects contrast. In this case, presumably, it contrasts with an implicit generic operator (i.e. usually) in a sentence without ozik such as Jeoneun gichareul tamnida 'I take the train.' Hence, if ozik replaces the implicit generic operator, then its function is to emphasize the fact that the proposition Jeoneun gichareul tamnida 'I take the train' holds at all times under consideration. If this is the case, it is reasonable to say that ozik exhibits prosodic prominence.
} 
discourse and is not in a contrastive relationship. Therefore, it should lack prosodic prominence via dephrasing.

\section{Conclusion}

This study has addressed the issue of whether or not the element associated with ozik can be dephrased in Korean. The question was answered by a perceptual experiment in which the pitch contours of the target sentences (i.e. Jeoneun ozik gichareul tamnida 'I only take the train' and Jeoneun ozik daehanhanggongeul iyonghamnida. 'I only take Korean Air.') were modified using Praat. The target sentences were then embedded in two competing contexts in which focus or GIVENness on the element associated with ozik (i.e. gichareul, daehanhanggongeul) was elicited. The results of this study demonstrated that DoubleH (where both the focusing adverb and the object have prosodic prominence) is shown to be the most favored prosodic model when the element associated with ozik is focused in discourse. In contrast, $\mathrm{OzikH}$ (where the focusing adverb has prosodic prominence) is shown to be most optimal when the element associated with ozik is GIVEN in discourse. Therefore, we argue that the element associated with ozik does not always have to be prominent, but instead the prosodic status of focus/GIVENness is constrained by the discourse.

This study provides an articulated view of how ozik and focus/GIVENness are managed in discourse by prosody. It demonstrates that Korean listeners make use of prosody to perceive the different levels between ozik and informational status that vary depending on the context.

\section{Acknowledgements}

I would like to thank Jiahong Yuan, Florian Schwarz, Catherine Lai, Georgia Zellou, and two anonymous reviewers for their comments and suggestions. Additionally, my sincere thanks go to Robert Wilder and Sora Kang for proofreading this paper. An earlier version of this paper was presented at the $38^{\text {th }}$ Annual Meeting of the Berkeley Linguistics Society.

\section{References}

1. Avesani C, Vayra M. Accenting, deaccenting, and information structure in Italian dialogues. In: Dybkjaer L, Minker W, editors. Proceedings of the 6th DIGdial Workshop on Discourse and Dialogue; 2005 Sep 2-3; Lisbon; 2005. p.19-24.

2. Bartels C. Acoustic correlates of 'second occurrence' focus: towards an experimental investigation. In: Kamp H, Partee B, editors. Context-dependence in the analysis of linguistic meaning. Amsterdam: Elsevier; 2004. p.354361. 
3. Bartels C, Kingston J. Salient pitch cues in the perception of contrastive focus. In: Bosch P, van der Sandt R, editors. Focus and natural language processing, Vol. 1: Intonation and syntax. Heidelberg: Working papers of the IBM Institute for Logic and Linguistics; 1994. p.1-10.

4. Baumann S. Degrees of givenness and their prosodic marking. Paper presented at the International Symposium on "Discourse and prosody as a complex interface", 2005 Sep 8-9; Aix-en-Provence.

5. Baumann S, Hadelich K. On the perception of intonationally marked givenness after auditory and visual priming. Proceedings of the AAI Workshop "Prosodic Interfaces”. Nantes; 2003. p.21-26.

6. Beaver D, Clark B. The proper treatments of focus sensitivity. In: Mikkelsen L, Potts C, editors. Proceedings of the 21st West Coast Conference on Formal Linguistics. Somerville: Cascadilla Press; 2002. p.15-28.

7. Beaver D, Clark B. Always and only: Why not all focus-sensitive operators are alike. Natural Language Semantics. 2003;11:323-362.

8. Beaver D, Clark B, Flemming E, Jaeger F, Wolters M. When semantics meets phonetics: Acoustical studies of second-occurrence focus. Language. 2007;83(2): 245-276.

9. Boersma P, Weenink D. Praat: doing phonetics by computer [computer software]. 1999-2012.

10. Büring D, Hartmann K. The syntax and semantics of focus-sensitive particles in German. Natural Language and Linguistic Theory. 2001;19(2):229-281.

11. Cruttenden A. The de-accenting of given information: A cognitive universal? In: Bernini G, Schwartz M, editors. Pragmatic organization of discourse in the languages of Europe. The Hague: Mouton de Gruyter; 2006. p.311356.

12. Dohen M, Lœvenbruck H. Interaction of audition and vision for the perception of prosodic contrastive focus. Language and Speech. 2009;52:177-206.

13. Féry C, Ishihara S. The phonology of second occurrence focus. Journal of Linguistics. 2009;45(2):285-313.

14. Fowler C, Housum J. Talkers' signaling of "new" and "old" words in speech and listeners' perception and use of the distinction. Journal of Memory and Language. 1987;26:489-504.

15. Halliday MAK. Intonation and grammar in British English. The Hague: Mouton; 1967.

16. Hartmann K, Zimmermann M. Not only 'only', but 'too', too: Alternative-sensitive particles in Bura. In: Grønn A, editor. Proceedings of Sinn und Bedeutung 12; 2007 Sep 20-22; Oslo; 2008. p.196-211.

17. Haviland SE, Clark HH. What's new? Acquiring new information as a process in comprehension. Journal of Verbal Learning and Verbal Behavior. 1974;13(5):512-521.

18. Hirschberg J, Ward G. Accent and bound anaphora. Cognitive Linguistics. 1991;2(2):101-121.

19. Jackendoff R. Semantic interpretation in generative grammar. Cambridge: MIT Press; 1972. 
20. Jacobs J. The syntax of bound focus in German. Groninger Arbeiten zur Germanistischen Linguistik. 1984;25:172-200.

21. Jannedy S. Prosodic focus in Vietnamese. In: Ishihara S, Jannedy S, Schwarz A, editors. Interdisciplinary Studies on Information Structure 08; 2007. p.209-230.

22. Jun S-A. The Phonetics and Phonology of Korean Prosody [PhD thesis]. Columbus: The Ohio State University; 1993.

23. Jun S-A. The accentual phrase in the Korean prosodic hierarchy. Phonology. 1998;15(2):189-226.

24. Jun S-A. Intonational phonology of Seoul Korean revisited. In: Vance TJ, Jones K, editors. Japanese/Korean Linguistics 14. Stanford: CSLI; 2006. p.15-26.

25. Jun S-A. Prosodic markings of complex NP focus, syntax, and the pre-/post-focus string. In: Washburn MB, McKinney-Bock K, Varis E, Sawyer A, Tomaszewicz B, editors. Proceedings of the 28th West Coast Conference on Formal Linguistics. Somerville: Cascadilla Press; 2011. p.214-230.

26. Kadmon N. Formal pragmatics: Semantics, pragmatics, presupposition, and focus. Oxford: Blackwell; 2001.

27. Krahmer E, Swerts M. On the alleged existence of contrastive accents. Speech Communication. 2001;34:391405 .

28. Krahmer E, Ruttkay Z, Swerts M, Wesselink W. Pitch, eyebrows, and the perception of focus. Proceedings of the Speech Prosody 2002; 2002 Apr 11-13; Aix-en-Provence; 2002. p.443-446.

29. Krifka M. Focus and/or context: A second look at second occurrence expressions. In: Kamp H, Partee B, editors. Context-dependence in the analysis of linguistic meaning. Amsterdam: Elsevier; 2004. p.187-207.

30. Krifka M. Association with focus phrases. In: Molnar V, Winkler S, editors. The architecture of focus. Berlin, New York: Mouton de Gruyter; 2006. p.105-136.

31. Ladd DR. Intonational phonology. Cambridge: Cambridge University Press; 1996.

32. Lee C. 2003. Contrastive topic and/or contrastive focus. In: McClure B, editor. Japanese/Korean linguistics 12. Stanford: CSLI; 2003. p.1-13.

33. Lee Y-c, Nambu S. Prosody and semantics of the focus particles always and only in Korean: Theoretical implications from a perception experiment. University of Pennsylvania Working Papers in Linguistics. 2012;18(1):151-159. [accessed 10 May 2012]. Available from: http://repository.upenn.edu/pwpl/vol18/iss1/18/.

34. Lee Y-c, Xu Y. Phonetic realization of contrastive focus in Korean. Proceedings of the Speech Prosody 2010; 2010 May 10-14; Chicago; 2010. p.100033:1-4.

35. Liu F. Intonation systems of Mandarin and English: A functional approach. [PhD thesis]. Chicago: University of Chicago; 2009. 
36. Nooteboom SG, Kruyt JG. Accents, focus distribution, and the perceived distribution of given and new information: An experiment. Journal of the Acoustical Society of America. 1987;82(5):1512-1524.

37. Partee B. Topic, focus and quantification. In: Moore SK, Wyner AZ, editors. Proceedings of the 1st Semantics and Linguistic Theory Conference. 1991 Apr 19-21; Ithaca; 1991. p.159-188.

38. Partee B. Focus, quantification, and semantics-pragmatics issues. In: Bosch P, van der Sandt R, editors. Focus: Linguistics, cognitive, and computational perspectives. Cambridge University Press; 1999. p.213-231.

39. Rochemont M, Culicover P. English focus constructions and the theory of grammar. Cambridge: Cambridge University Press; 1990.

40. Rooth M. A theory of focus interpretation. Natural Language Semantics. 1992;1:75-116.

41. Rooth M. Focus. In: Lappin S, editor. Handbook of contemporary semantic theory. Oxford: Blackwell; 1996. p.271-297.

42. Schafer A, Jun S-A. Effects of accentual phrasing on adjective interpretation in Korean. In: Nakayama M, editor. East Asian Language Processing. Stanford: CSLI; 2002. p.223-55.

43. Schütze C, Sprouse J. Judgment data. In: Sharma D, Podesva R, editors. Research Methods in Linguistics; To $\begin{array}{llllll}\text { appear. } & \text { [accessed } & 14 & \text { Nov } & \text { Available }\end{array}$ http://www.socsci.uci.edu/ jsprouse/papers/ch3.judgment.data.pdf

44. Schwarzschild R. Why some foci must associate; 1997. [accessed 25 Dec 2011]. Available from: http://lumiere.ens.fr/ bspector/SemPrag06/Schwhartzchild_Focus.pdf.

45. Schwarzschild R. GIVENness, AvoidF and other constraints on the placement of accent. Natural Language Semantics. 1999;7:141-177.

46. Selkirk E. Contrastive focus, givenness and unmarked status of "discourse new". Acta Linguistica Hungarica. 2008;55:1-16.

47. Sudhoff S. 2010. Focus particles and contrast in German. Lingua. 2010;120(6):1458-1475.

48. $\mathrm{Xu} \quad \mathrm{Y}$. TimeNormalizeF0.praat. [accessed 31 Aug 2011]. Available from: http://www.phon.ucl.ac.uk/home/yi/tools.html. 2005-2012.

\section{Appendix}

Two competing discourse contexts served as the experimental stimuli. The original Korean data (a) are listed first, followed by the Revised Romanization of Korean (b), and the English translations (c). The target sentences are in boldface, and the elements associated with ozik are in square brackets. The subscripted F, G, and CF represent discourse-new focus, GIVENNESS, and contrastive focus, respectively. 
Lee, $Y-c$.

1. Discourse-new focus (The element associated with ozik is discourse-new.)

a. 저는 대전에 있는 한남대학교에 다닙니다. 그런데 저의 고향은 서울이며 부모님은 현재 서울에 살고 계십니다. 하지만 저의 동생은 부산에 살고 저의 형님께서는 대구에 살고 계십니다. 그래서 명절이 되면 대중교통수단을 이용해서 가족들을 만나러 서울, 부산, 대구를 방문하곤 합니다. 부모님을 만나기 위해서 서울을 방문할 때, 저는 오직 [기차를] $F_{F}$ 탑니다.

b. Jeoneun daejeone inneun hannamdaehakgyoe danimnida. Geureonde jeoui gohyangeun seourimyeo bumonimeun hyeonjae seoure salgo gyesimnida. Hajiman jeoui dongsaengeun busane salgo jeoui hyeongnimkkeseoneun daekue salgo gyesimnida. Geuraeseo myeongjeori doemyeon daejunggyotongsudaneul iyonghaeseo gajokdeureul mannareo seoul, busan, daegureul bangmunhagon hamnida. Bumonimeul mannagi wihaeseo seoureul bangmunhal ttae, jeoneun ozik [gichareul $]_{\mathrm{F}}$ tamnida.

c. I am attending Hannam University in Daejeon. However, my parents live in Seoul, my younger brother lives in Busan, and my older brother lives in Daegu. So, on major holidays, such as Christmas and New Year's Day, I may go to Seoul, Busan and Daegu to visit my family. When going to Seoul to see my parents, I only take [the train $]_{\mathrm{F}}$.

2. GIVENness (The element associated with ozik is GIVEN.)

a. 저의 아버지는 코레일 회사에 다니십니다. 코레일 회사의 규정에 따르면 직원의 가족인 경우에는 기차표가 공짜입니다. 저는 회사 업무로 인해서 서울로 출장을 가는 경우가 많습니다. 그래서 서울에 갈 때마다, 저는 오직 [기차를 $]_{G}$ 탑니다.

b. Jeoui abeojineun koreil hoesae danisimnida. Koreil hoesaui gyujeonge tareumyeon jigwonui gajogin gyeongueneun gichapyoga gongjjaimnida. Jeoneun hoesa eommuro inhaeseo seoullo chuljangeul ganeun gyeonguga manseumnida. Geuraeseo seoure gal ttaemada, jeoneun ozik [gichareul $]_{\mathrm{G}}$ tamnida.

c. My father works for Korail. According to Korail regulations, my family gets free train tickets. I take business trips to Seoul. So, whenever I go to Seoul, I only take [the train $]_{\mathrm{G}}$.

3. Contrastive focus (The element that associates with ozik is contrastive.)

JoSS 2(2): 85-111. 2012 
a. 저는 미국 필라델피아에 있는 펜실베이니아 대학교에 다닙니다. 하지만 부모님이 한국에 살고계시기 때문에 부모님을 뵙기 위해서 방학마다 한국에 갑니다. 저는 대한항공과 델타항공 마일리지 카드를 모두 가지고 있습니다. 미국에서 한국으로 갈 때, 저는 오직 [대한항공을] $]_{\mathrm{CF}}$ 이용합니다.

b. Jeoneun miguk pilladelpiae inneun pensilbeinia daehakgyoe danimnida. Hajiman bumonimi hanguge salgogesigi ttaemune bumonimeul boepgi wihaeseo banghangmada hanguge gamnita. Jeoneun daehanhanggonggwa deltahanggong mailliji kadeureul modu gajigo itseumnida. Migugeseo hangugeuro gal ttae, jeoneun ozik [daehanhanggongeul $]_{\mathrm{CF}}$ iyonghamnita.

c. I am attending the University of Pennsylvania in Philadelphia. However, since my parents live in Korea, I go to Korea to see them every school vacation. I have both Korean Air and Delta Airline membership cards. When I go to Korea, I only take [Korean Air $]_{\mathrm{CF}}$.

4. GIVENness (The element that associates with ozik is GIVEN.)

a. 저는 뉴욕에 있는 콜럼비아 대학교에 다닙니다. 하지만 부모님이 한국에 살고 계셔서 방학이면 부모님을 뵙기 위해서 한국에 갑니다. 저는 대한항공 마일리지 카드를 갖고 있기 때문에 다른 항공사는 이용하지 않습니다. 그래서 방학에 한국에 갈 때마다, 저는 오직 [대한항공을] $]_{\mathrm{G}}$ 이용합니다.

b. Jeoneun nyuyoge itneun kolleombia daehakgyoe danimnida. Hajiman bumonimi hanguge salgo gyesyeoseo banghagimyeon bumonimeul boepgi wihaeseo hanguge gamnida. Jeoneun daehanhanggong mailliji kadeureul katgo itgi ttaemune dareun hanggongsaneun iyonghaji anseumnida. Geuraeseo banghage hanguge gal ttaemada, jeoneun ozik [daehanhanggongeul $]_{\mathrm{G}}$ iyonghamnita.

c. I am attending Columbia University in New York. However, since my parents live in Korea, I go to Korea to see them every school vacation. Because I have a Korean Air membership card, I don't take other airlines. So, whenever I go to Korea, I only take [Korean Air $]_{\mathrm{G}}$. 